\title{
O consumo e suas articulações com os relacionamentos amorosos
}

\author{
Consumption and its articulations with loving relationships
}

\author{
Bruno Medeiros Ássimos ${ }^{1}$ \\ Marcelo de Rezende Pinto ${ }^{2}$ \\ Suzana Melgaço de Afonseca ${ }^{3}$
}

\begin{abstract}
Resumo
Este trabalho relata resultados de uma pesquisa cujo objetivo foi compreender como o consumo se estabelece na dinâmica da construção das relações amorosas de um casal. A justificativa para o trabalho reside na constatação de que são necessários mais estudos que conectem as emoções presentes em determinados contextos, como as relações amorosas, ao tema consumo. Adotou-se a perspectiva interpretativa de investigação fornecida pela Consumer CultureTheory (CCT), direcionada pelo arcabouço epistemológico-metodológico da GroundedTheory. No trabalho de campo, foram conduzidas 15 entrevistas em profundidade. Além disso, a pesquisa também contou com a utilização de técnicas projetivas. A análise dos dados permitiu a elaboração de um esquema teórico no qual foram explicitados diversos elementos caros ao campo do consumo em uma perspectiva cultural e simbólica. Como conclusão, percebeu-se a maneira pela qual o consumo está imbricado às relações amorosas, uma vez que funciona como expressão do indivíduo, é elemento fundamental em momentos de conquista, ao mesmo tempo em que propicia o meio pelo qual a relação poderá consolidar e se manter por meio da integração das identidades.
\end{abstract}

Palavras-chave: Cultura. Consumo. Amor. Identidade.

\begin{abstract}
This paper reports results of a research whose objective was to understand how the consumption is established in the dynamics of the construction of the amorous relationships of a couple. The justification for the work lies in the fact that more studies are needed that connect the emotions present in certain contexts, such as love relationships, to the consumption theme. The interpretative perspective of research provided by the Consumer Culture Theory (CCT), guided by the epistemologicalmethodological framework of Grounded Theory, was adopted. In the field work, 15 in-depth interviews were conducted. In addition, the research also relied on the use of projective techniques. The analysis of the data allowed the elaboration of a theoretical scheme in which several expensive elements were explained to the field of consumption in a cultural and symbolic perspective. As a conclusion, the way in which consumption is intertwined with love relations is perceived, since it functions as an expression of the individual, it is a fundamental element in moments of conquest, while at the same time providing the means by which the relationship can consolidate and maintained through the integration of identities.
\end{abstract}

Keywords:Culture. Consumption. Love. Identity.

\section{Introdução}

O consumo tornou-se nas últimas décadas um fenômeno que, a despeito de todas as discussões dispensadas para a produção, passou a ser considerado como o elemento central para se entender a sociedade atual (BARBOSA, 2006; DESJEUX, 2011; WARDE, 2017). Ou seja, pode-se afirmar que o consumo

\footnotetext{
Doutorando em Administração pela Pontifícia Universidade Católica de Minas Gerais. Afiliação: Universidade Católica de Minas Gerais. Brasil. Lattes: http://lattes.cnpq.br/5796310342153209 Email: bruno.assimos@gmail.com

2 Doutor em Administração pela UFMG. Professor do Programa de Pós-Graduação em Administração da Pontifícia Universidade Católica de Minas Gerais. Brasil. Lattes: http://lattes.cnpq.br/6011936684655367 Email: marcrez@hotmail.com

3 Mestre em Administração pela FEAD Minas. Professora da Graduação em Administração da Pontifícia Universidade Católica de Minas Gerais. Afiliação: Universidade Católica de Minas Gerais. Brasil. Lattes: http://lattes.cnpq.br/9020538467556473 Email: suzanamelgaco@gmail.com
} 
se conecta com diversos elementos centrais da cultura e da sociedade contemporânea (BARBOSA, 2006), assim como parece ser um importante indicador da vida cotidiana, dos modos de vida e das construções identitárias dos sujeitos e grupos e das estratificações sociais (DESJEUX, 2011).

Ao mesmo tempo, pode-se perceber que a vida nessa mesma sociedade encontra-se permeada por relações imbuídas de sentimentos e emoções. Nesse contexto, emergem as relações amorosas que, assim como o consumo, também acompanharam as mudanças sociais ocorridas ao longo dos tempos(ILLOUZ, 2011).

Cabe mencionar que o elemento central nas relações amorosas, conforme defende Illouz (2011), está relacionado ao consumo massivo de rituais, mesmo que particulares ao universo do casal. São eles que revigoram o mercado e os amantes, que ao abandonarem o cotidiano para entrar no mundo especial do consumo romântico, se desligam do consumo puramente utilitarista.Dessa forma, não se pode deixar de considerar que as relações amorosas estão sob a interferência dos mecanismos de produção e distribuição de bens e serviços próprios do capital, diferindo-se apenas pelo uso simbólico distintivo que os amantes fazem dos produtos associados ao amor romântico. Ou seja,como prática cultural, as relações amorosas estão incorporadas em um amplo leque de produtos, objetos, locais e rituais. Torna-se importante ressaltar que, nas sociedades contemporâneas, o consumo está presente em diversas esferas do amor romântico, oferecendo produtos culturais que marcam os ideais e sentimentos amorosos, além de contextos para a vivência dos rituais românticos (COSTA, 2005).

O alinhamento da ideia de que o consumo é algo bastante presente na vida das pessoas no contexto da sociedade atual com a noção de que o consumo romântico acaba sendo um tipo de consumo especial, faz surgir uma lacuna teórica que se mostra oportuna para o campo da cultura e consumo. Isso porque se percebe que indivíduos diferentes, ao lançarem-se em um relacionamento amoroso, passam a (re)significar o consumo de diversos produtos e serviços e construir um "modo" diferente e próprio de consumo da relação que pode ser diverso dos indivíduos separadamente. É como se o casal tivesse uma forma própria de consumo que vai servir para expressar a própria relação.

Essa lacuna, que serviu de motivação para o presente estudo, parece estar em linha com o campo da Consumer CultureTheory (CCT), tendo em vista que sua proposta é relacionar questões articulando consumo, cultura e mercados (ARNOULD e THOMPSON, 2005; 2007).A partir daí, coloca-se como pergunta norteadora do trabalho a seguinte indagação: como são (re)construídos os significados do consumo a partir da dinâmica da construção da relação amorosa de um casal? Para que a pergunta seja respondida, o propósito geral deste trabalhovisa compreender como o consumo se estabelece na dinâmica da construção das relações amorosas de casais heterossexuais, envolvendo homem e mulher com faixa etária entre 24 (vinte e quatro) e 39 (trinta e nove) anos, e vivenciando um relacionamento amoroso de até dois anos de duração..

Com fins de se atingir esse objetivo, adotou-se a perspectiva interpretativa de investigação fornecida pela Consumer CultureTheory (CCT), direcionada pelo arcabouço epistemológico-metodológico da GroundedTheory. O direcionamento quanto ao uso da GroundedTheory proposto por Charmaz (2009) foi adotado dado sua maior aderência ao objetivo da pesquisa. A autora incentiva o pesquisador a elaborar uma contribuição teórica fundamentada nos dados do campo por meio do uso construtivista-interpretativista da GroundedTheory(CHARMAZ, 2009). Como principal método de coleta de dados, foram entrevistadas 15 (quinze) pessoas em profundidade. É importante lembrar que lançou-se mão também da utilização de técnicas projetivas.

Este trabalho encontra sua justificativa na necessidade de maior exploração de estudos que conectem as emoções presentes em determinados contextos, como as relações amorosas, ao tema consumo (SAUERBRONNet al., 2009). Além disso, outras justificativas podem ser apresentadas. Em primeiro lugar, é importante levar em conta que a questão do relacionamento amoroso pode ser um caminho revelador para se entender aspectos do consumo e suas articulações para outras esferas da vida cotidiana. Em segundo lugar, a utilização da GroundedTheory ainda é pequena no campo da CCT (BELKet al., 2013). Com sua utilização, os pesquisadores podem contar com uma metodologia de caráter indutivo que contribui para entender aspectos da vida cotidiana dos indivíduos a partir da realidade dos sujeitos pesquisados (PINTO e SANTOS, 2012). Por fim, ainda cabe ressaltar que a articulação entre consumo e relações amorosas pode jogar luz e contribuir para avançar no entendimento de outras questões relacionadas à vida social. 


\section{Literatura sensibilizadora}

Estudos baseados em GroundedTheory se utilizam de conceitos sensibilizadores da literatura, os quais oferecem uma inspiração incipiente, devendo ser revisitados durante o percurso do pesquisador em campo e, principalmente, após a finalização desta etapa, em uma posição de abertura e construção do referencial ao longo de todo o trabalho (CHARMAZ, 2009). Nesse sentido, essa seção dedicou espaço à discussão de duas temáticas que parecem conter elementos sensibilizadores acerca do fenômeno que se buscou investigar, ou seja, as formas de (re)construção dos significados do consumo a partir da dinâmica da construção da relação amorosa de um casal. De início, foi priorizada uma discussão breve sobre o consumo em uma perspectiva cultural e simbólica que acaba por conduzir o leitor às premissas da CCT e, em seguida, jogou-se luz sobre comentários acerca dos enlaces teóricos entre as relações amorosas, o amor romântico e o consumo.

\section{O consumo em uma perspectiva cultural e simbólica}

É possível compreender que indivíduos de culturas diferentes possam ser identificados por uma série de características, tais como o modo de agir, vestir, caminhar, comer, consumir, sem mencionar a evidência das diferenças linguísticas, o fato de mais imediata observação empírica (LARAIA, 2002; BARBOSA, 2004; MCCRACKEN, 2003; ROCHA, 2000). Entretanto, não há ordem social baseada em verdades absolutas, alterações no ambiente provocam mudanças de comportamento, afirmando o aspecto evolutivo da cultura, que se molda conforme determinados comportamentos vão sendo incorporados, modificados ou excluídos ao longo do tempo (HARRIS, 1969).

A compreensão da relação entre cultura e consumo constitui tema de reflexão para outros autores. Gaião, Souza e Leão (2012, p.332) afirmam que "em contraste com a tradicional visão antropológica de pessoas como portadores de cultura, os consumidores são vistos como produtores de cultura", em sintonia com o pensamento de autores como Baudrillard (1995), Rocha (2000), McCracken (2003), Barbosa (2004) e Campbell (2006). Estes autores (Baudrillard, 1995; Rocha, 2000; McCracken, 2003; Barbosa, 2004; Campbell, 2006) vão além da visão tradicional de cultura como via de mão única, sociedade-indivíduo, para a via indivíduo-sociedade, confirmando que os aspectos culturais estão em constante transformação e são passíveis de mudança instigada pelos próprios indivíduos. É importante levar em conta que a cultura permeia os aspectos mais substanciais da vida, proporcionando os pilares centrais da vida social.

Dessa forma, se a cultura muda, os hábitos também mudam e ela seguramente irá influenciar sobremaneira o marketing, residindo aí a importância de sua inclusão nos estudos mercadológicos (ARNOLDeTHOMPSON, 2005), tornando "necessário incorporar nos estudos de consumo questões referentes a aspectos socioculturais, experienciais, simbólicos e ideológicos" (PINTOeLARA, 2011, p.38). Em essência, o ato de consumir tem sentido cultural, atrelando seu significado às vivências culturais intrínsecas não só a cada grupo social, mas também ao indivíduo, transformando-se na expressão do estilo de vida (MILLER, 2007). Tais significados podem variar entre indivíduos e grupos sociais, modificando-se paralelamente às transformações culturais (BARBOSA, 2004; MCCRAKEN, 2007).

$\mathrm{Na}$ área do marketing e mais precisamente no campo do comportamento do consumidor, os estudos que optam pela utilização desse referencial teórico que priorizam a vertente social e culturalmente construída do consumo encontra respaldo sob a corrente chamada de Consumer CultureTheory (CCT). Essa corrente refere-se a uma família de perspectivas teóricas que direcionam as relações dinâmicas entre as ações de consumo, o mercado e os significados culturais (ARNOULD e THOMPSON, 2005).

Os autores aqui utilizados, incluindo os adeptos da CCT, defendem que a evolução para a sociedade do consumo alterou diversas dimensões da vida social, incluindo também a dinâmica das relações amorosas. Campbell (2001) defende que as relações amorosas se configuram como tema de grande importância para a ascensão da própria cultura de consumo. Não se pode deixar de mencionar que a sociedade de consumo é a relação indissociável indivíduo-consumo e o consumo é uma construção cultural e simbólica. Assim, indivíduos de diferentes culturas vivenciam a relação amorosa de diferentes maneiras, apresentando significados conforme, novamente, o tempo, espaço e situação (BEALL e STERNBERG, 1995; CAMPBELL, 2001). Essas questões serão discutidas na próxima seção. 


\section{As relações amorosas, o amor romântico e o consumo}

Os estudos que apresentaram algum nível de proposta no sentido de conceituar e mesclar os temas relações amorosas e consumo estão pulverizados por diversos campos do conhecimento, como a psicologia, a psicanálise, a economia, a história, etc. Guedes e Assunção (2006) e Campbell (2001) argumentam que as tratativas sociais das relações amorosas se modificaram ao longo do tempo.O amor romântico constitui-se como o último arranjo de amor presente nas relações amorosas, cuja origem se encontra na era da modernidade, mas que sofre algumas alterações na contemporaneidade. Assim, o amor romântico moderno baseia-se na busca do ser amado sem considerar as barreiras sociais existentes, podendo estar em qualquer lugar (CAMPBELL, 2001).

O amor romântico presente nas relações amorosas, segundo Costa (2005), é um modelo histórico cultural que se desdobra em cinco dimensões: campo das emoções, idealização, modelo de relação, prática cultural e interações sociais. No campo das emoções, o amor romântico se expressa como um vínculo com o outro que não conhece desejo mais ardente que a vontade de conduzir a própria vida no corpo da pessoa amada, tratando aqui a emoção não como uma resultante neurofisiológica, mas como uma construção ofertada por um legado cultural que molda identidades e determina contextos. Como idealização, o amor romântico promete o reconhecimento do indivíduo como pleno de sua unidade, reivindicando o ser e retirando força do entorno social; elemento este ainda mais importante nas sociedades contemporâneas, atuando como decisivo nas escolhas e comportamentos individuais. Como modelo de relação, condensam-se historicamente no amor romântico a unidade entre paixão sexual e afeição emocional, a unidadede amor e matrimônio e, frequentemente, os planos de constituição de uma prole.Como prática cultural, o amor romântico evoca, percebe, transmite e intensifica discursos, ações e rituais onde as emoções amorosas residem. As interações sociais, terreno da prática cultural, compreendem as relações de penetração em modelos de significação e interpretação de símbolos comunicativos tão pessoais que muitas vezes se tornam incompreensíveis para os que estão de fora da relação amorosa . A mera ruptura com a ordem é apenas uma migração entre esferas sociais, no qual os amantes abandonam o cotidiano e adentram no mundo do consumo romântico, local em que a indústria atrelada aos rituais pode atuar, como, por exemplo, nos passeios de carro, nas viagens à praia, nas idas à Europa, dentre muitos outros, todos eles oferecendo suporte e cenário para que os enredos amorosos sejam realizados (COSTA, 2005).

No amor que é incapaz de distinguir-se da cultura e do consumo, "as escolhas amorosas são construídas historicamente, com os respectivos códigos de interação e vinculação pessoais típicos de cada cultura" (PINHEIRO, 2006, p.177), assumindo que, como prática cultural, está inserido em um amplo leque de produtos, objetos, locais e rituais (COSTA, 2005); incorporação realizada pela indústria cultural e publicidade, e passível de ser ressignificada ou não, conforme McCracken (2007), preservando o conceito de empoderamento do consumidor, que assume ou não, modifica, cria ou mantém o que lhe é transmitido e transmite a outros. Pinheiro (2006) revela que a indústria cultural usa de seu poder de persuasão para imbuir elementos de consumo nas relações amorosas, que são validados e incorporados na vida social cotidiana. Para a autora, "... existe a busca de um olhar de aceitação e admiração do outro. ... busca-se amar alguém que seja legitimado socialmente, bonito [...], atraente [...], que esteja na moda e portando novas tecnologias. ...busca-se no outro a validação da auto-identidade" (PINHEIRO, 2006, p.185), o que reforça a necessidade de se compreender melhor como o consumo contribui para o molde de uma relação amorosa.

Alguns estudos que tangenciam a articulação entre consumo e relações amorosas no campo da CCT podem ser citados. Um deles é intitulado "BeyondtheExtended Self-LovedObjectsandConsumers' IdentityNarratives" (AHUVIA, 2005) e debate como consumidores expressam sua própria identidade por meio de narrativas e em meio a forças que impulsionam a fragmentação de uma identidade coerente, refletida em objetos e atividades significados pelas relações sociais. Outro trabalho foi conduzido por Ger e Belk (1999) sob o título "Accounting for Materialism in Four Cultures". O texto descrevea crença acerca do materialismo em quatro culturas distintas do globo, abarcando concepções históricas, culturais e éticas, e demonstrando que as culturas não são homogêneas quanto a tratativa do tema consumo. Pode ser citado também o artigo "The SacredMeaningsof Money" (BELK e WALLENDORF, 1990), no qual se discute que o significado do dinheiro é investigado em relação ao contexto e sua percepção como sagrado ou profano. 
Vale considerar o paper publicado por Belk e Coon (1991) intitulado "Can'tBuy me Love: Dating, Money, andGifts" que investigou o namoro estadunidense em seu contexto material, sexual e romântico por meio das atividades, gastos e presentes, descobrindo suas influências nas relações amorosas e servindo como parte da inspiração para este estudo. Por fim, pode-se citar ainda o texto "GiftGiving as Agapic Love: AnAltemativetothe Exchange ParadigmBasedonDatingExperiences" (BELK e GREGORY, 1993), ao qual investigou como o amor agápico (aquele em que envolve a capacidade concreta de doação de um amante em favor do outro) é expressado nas relações de trocas de presentes, dentre outros.

Sendo assim, esses estudos,os quais apresentam elementos que estão em linha com a literatura atinente à CCT, jogam luz sobre a relação entre consumo e relações amorosas. Isto é, cabe ressaltar que, de alguma forma, o consumo está imbricado aos relacionamentos amorosos, algoque foi objeto do presente estudo e será discutido nas próximas seções.

\section{Percurso Metodológico}

Inicialmente, cabe salientar que este trabalho utilizou a GroundedTheory como método de pesquisa. Dada a natureza pouco explorada do tema, a GroundedTheory constituiu-se como o método aderente ao objetivo da pesquisa, levando em conta que a proposta não se limita unicamente a uma descrição do fenômeno, mas a elaboração de uma contribuição teórica fundamentada nos dados coletados a partir dos relatos dos participantes do estudo (CHARMAZ, 2009). A principal autora orientadora quanto ao uso da GroundedTheory nesta pesquisa foi Charmaz (2009), por trabalhar em uma perspectiva interpretativista e construtivista, abordagens adequadas a um trabalho de natureza indutiva. A escolha de Charmaz (2009) se alinha com a proposta do artigo pelo fato de se buscar construir o entendimento da realidade a partir da realidade dos sujeitos pesquisados. Dito de outra forma, em uma pesquisa de natureza indutiva, os elementos analisados emergem do trabalho de campo e não da revisão da literatura.

O instrumento utilizado para a produção de dados utilizado foi o roteiro semiestruturado e o método adotado foi a entrevista em profundidade; a adaptação dessa combinação aos métodos da GroundedTheory é profícua (CHARMAZ, 2009). Inicialmente, foram realizadas quatro entrevistas com quatro indivíduos que atendessem ao perfil do grupo de interesse, durante este processo lhes foi pedido que contassem a história da formação do relacionamento, como o casal se conheceu e como ocorreu a aproximação. Ao longo da narrativa, perguntas livres presumidamente relevantes eram realizadas, tomando-se por base os conceitos sensibilizadores da literatura (CHARMAZ, 2009). Além da literatura, as vivências pessoais e profissionais do pesquisador constituem fontes de sensibilidade aos dados (STRAUSS e CORBIN, 2008).

A partir dessas histórias, a primeira versão do roteiro semiestruturado, contendo 50 (cinquenta) questões, foi elaborado. Logo, a inspiração para a construção do roteiro emergiu do próprio campo. As questões remetiam a assuntos relativos ao relacionamento (atividades, locais, reconhecimento), aos presentes e à percepção do futuro. No momento da entrevista, a critério do entrevistador, eram selecionadas as questões mais aderentes a partir das respostas do entrevistado. Ou seja, as entrevistas foram conduzidas tendo por base as características indutivas da pesquisa. A análise das entrevistas propiciou a elaboração daprimeira versão de um esquema cujo objetivo era funcionar como contribuição teórica. Uma versão final desse esquema será apresentada na seção de análise dos dados (Figura 3).

Todas as entrevistas foram realizadas em local, dia e horário escolhido pelos participantes, sendo eles residência, local de trabalho ou cafeteria. Todas tiveram o áudio gravado e foram transcritas, totalizando 720 (setecentos e vinte) minutos de gravação e 356 (trezentas e cinquenta e seis) páginas de transcrição. Para Bauer eGaskell (2002), o número adequado de entrevistados situa-se entre 15 (quinze) a 25 (vinte e cinco) e cada uma delas deve contribuir para o preenchimento de lacunas (FLICK, 2004).. Definiu-se por grupo de interesse, homens e mulheres que se declararam nas seguintes condições: heterossexuais, com faixa etária entre 24 (vinte e quatro) e 39 (trinta e nove) anos, e vivenciando um relacionamento amoroso de até dois anos de duração.A opção por estudar este público e com este recorte se deu por iniciativa livre do pesquisador(BAUER and GASKELL, 2002) tendo em vista que é nessa fase da vida que as pessoas tendem a procurar uniões mais estáveis . 
A técnica de amostragem utilizada foi a teórica, na qual a construção da amostra utilizada é realizada e repensada a cada entrevista, objetivando a melhor sustentação possível à contribuição teórica a ser criada, ou seja, a seleção é gradual e ocorre por meio da seleção e integração intencional de novos casos (DENZIN e LINCOLN, 2006; CHARMAZ, 2009), sendo esta a melhor maneira para se trabalhar com a GroundedTheory (CRESWELL, 2004; CHARMAZ, 2009).

De maneira complementar e com o objetivo de enriquecer a pesquisa, foi aplicada uma técnica inspirada nas técnicas projetivas ao final de cada entrevista. O uso desta inspiração se justifica pela percepção de que muitas vezes não é possível obter determinadas informações acerca do que realmente pensam as pessoas por meio de questionamentos diretos, especialmente quando assuntos mais íntimos estão em pauta e perante a presença de um entrevistador estranho. Além disto, as pessoas não possuem total controle sobre tudo o que as motiva, obtendo inspiração muitas vezes inconscientes (HAIRE, 1950). No momento em que responde a uma entrevista, o participante receia parecer irracional ou tolo e por isso, pode omitir ou negar determinados tipos de comportamento ou pensamento (DONOGHUE, 2000). As convenções sociais também podem ser obstáculos para a real expressão do indivíduo, fazendo-o conceder respostas que são socialmente aceitáveis ou estereotipadas (GREEN, 1984). Em pesquisas de marketing e consumo, as técnicas projetivas devem ser relativamente ambíguas para que os indivíduos encontrem espaço de interpretação e expressão em termos de suas próprias percepções e palavras. No entanto, elas devem oferecer orientação suficiente para que o indivíduo possa realizar alguma associação com o objeto de interesse da pesquisa (CHURCHILL, 1991).Muitos são os motivos para a utilização de técnicas projetivas e entrevistas nas pesquisas e seu uso deveria ser mais incentivado nas pesquisas de marketing e consumo (BELKet al., 2013).

Julgou-se mais adequada a utilização de um instrumento baseado no TAT (Teste de Apercepção Temática) por apresentar algumas características que se alinham melhor aos estudos de marketing e consumo. Por exemplo, o TAT permite o uso de imagens que podem ser modificadas para o uso em pesquisas do consumidor (KASSARJIAN, 1974; CHURCHILL, 1991). Seus temas envolvem a entrega de uma ou de um conjunto de imagens ou fotos cujo participante é convidado a descrever ou assumir o papel das pessoas que ali estão, dizendo o que estão pensando, dizendo e fazendo, ou seja, o participante é convidado a construir uma história em torno das imagens (CHURCHILL, 1991; DONOGHUE, 2000).Em síntese, técnicas projetivas são métodos que ajudam os participantes a dizerem coisas indiretamente que normalmente são difíceis de serem ditas de maneira direta, especialmente úteis para temas sensíveis ou com tendência de respostas socialmente desejáveis, como é o caso deste trabalho. Os métodos projetivos aplicados são normalmentedivertidos e quebram a rotina comum de uma entrevista, e para tal, devem ser escolhidos de acordo com os objetivos do estudo (MOISANDER et al., 2009apudBELKet al., 2013).Este trabalho se utilizou de duas imagens retiradas de campanhas de empresas do setor de cosméticos e moda. Cada uma delas, contendo oito (8) personagens cada, apresenta diversos tipos físicos de mulheres e homens usando apenas roupa íntima, o que minimiza o julgamento por vestuário, conforme figuras 1 e 2 .

Figura 1 - Campanha Dove Mulheres Reais

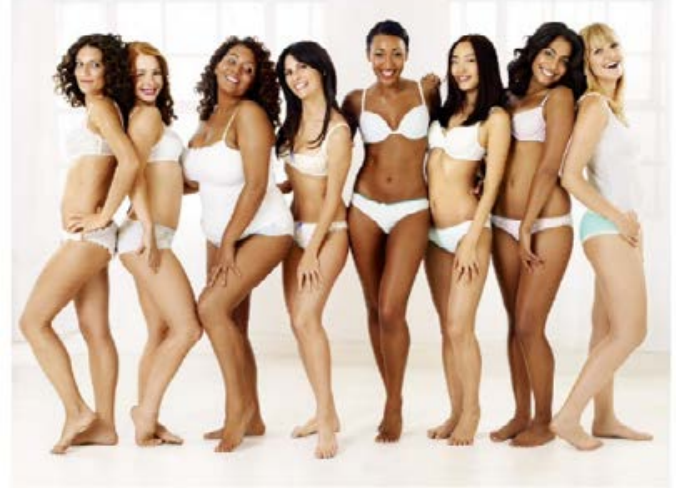

Fonte: Extraído do site www.dove.com.br
Figura 2 - Campanha UnderAmour

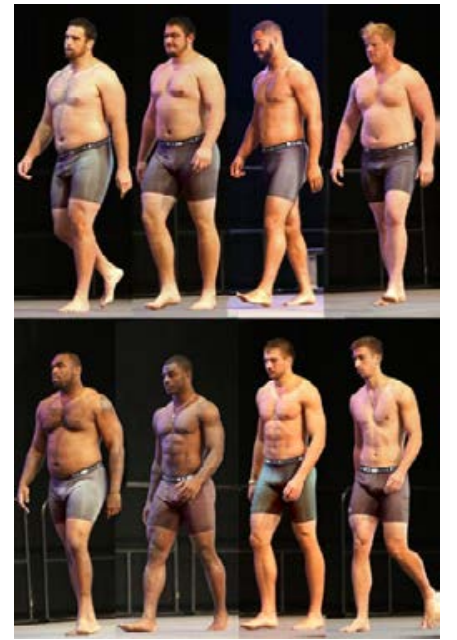

Fonte: Extraído do site enderarmour.com.br 
No início da aplicação da técnica projetiva, foi solicitado aos entrevistados que formassem livremente um casal e justificassem suas escolhas. Suas respostas compuseram o processo de análise deste estudo, especialmente no tocante a atributos de atração física e elementos que pudessem revelar os pontos de conquista e aproximação da relação amorosa.

Os entrevistados foram identificados para letra "E" seguido de um número, para preservar a identidade.A visão de Charmaz (2009) profere que a análise dos dados deve começar pela codificação inicial, que pode ocorrer palavra por palavra, linha a linha e/ou incidente por incidente. A segunda fase da codificação é nomeada de codificação focalizada por Charmaz (2009), nesta etapa, a codificação é mais direcionada, seletiva e conceitual que a etapa anterior. Os códigos anteriores mais relevantes e frequentes são empregados para analisar a soma final dos dados, exigindo que se revele quais códigos iniciais permitirão o melhor entendimento analítico para categorização dos dados (CHARMAZ, 2009). A última fase consiste na codificação teórica, que é a sequência da fase anterior e inclui o agrupamento de categorias em um fenômeno central de característica abstrata, permitindo o desenvolvimento de uma GroundedTheory (FLICK, 2004). Logo, para Charmaz (2009), e assim adotado por este trabalho, primeiro ocorre a construção de códigos, que se tornam categorias que consolidam as experiências dos participantes. Estas categorias se transformam em um esquema analítico "... que interpreta o que acontece e estabelece relações entre os processos implícitos e as estruturas visíveis" (CHARMAZ, 2009, p.83).

Nas etapas de pré-campo e fases 2 (dois), 3 (três) e 4 (quatro), foram criados 511 (quinhentos e onze) códigos, representando as principais questões identificadas na análise das entrevistas, finalizando a codificação inicial. Na fase 5 (cinco) foram criadas 10 (dez) categorias de análise em uma condensação dessas questões por aproximação e relação, perfazendo a etapa de codificação focalizada da GroundedTheory. 0 processo foi conduzido eletronicamente pelo uso de computador, objetivando maior facilidade no processo de organização, localização, de exame, visualização, e recuperação de dados (CRESWELL, 2014) e se deu por meio do software Atlas ti, versão 4.1. Este software possibilitou a organização de qualquer achado de uma pesquisa, auxiliando na realização da codificação, compara segmentos de informação, efetua buscas rápidas e a interface visual descomplica a condução e análise da pesquisa (CRESWELL, 2014), sendo substancial como agente facilitador do bom andamento de todo o procedimento científico.

\section{Análise, interpretação e esquema teórico}

O esquema teórico (figura 3) funciona como uma representação visual, refinada, didática, científica e facilitada do que foi absorvido na fase de produção e análise de dados. Cabe afirmar que o esquema teórico representa graficamente a articulação das categorias emergentes das fases de coleta e análise de dados tal como preconizada por Charmaz (2009). Todos os elementos participantes do esquema se mostraram necessários e estão fundamentados nos dados produzidos no campo, no referencial teórico inicial e no referencial teórico aqui revisitado. 
Figura 3: Esquema teórico

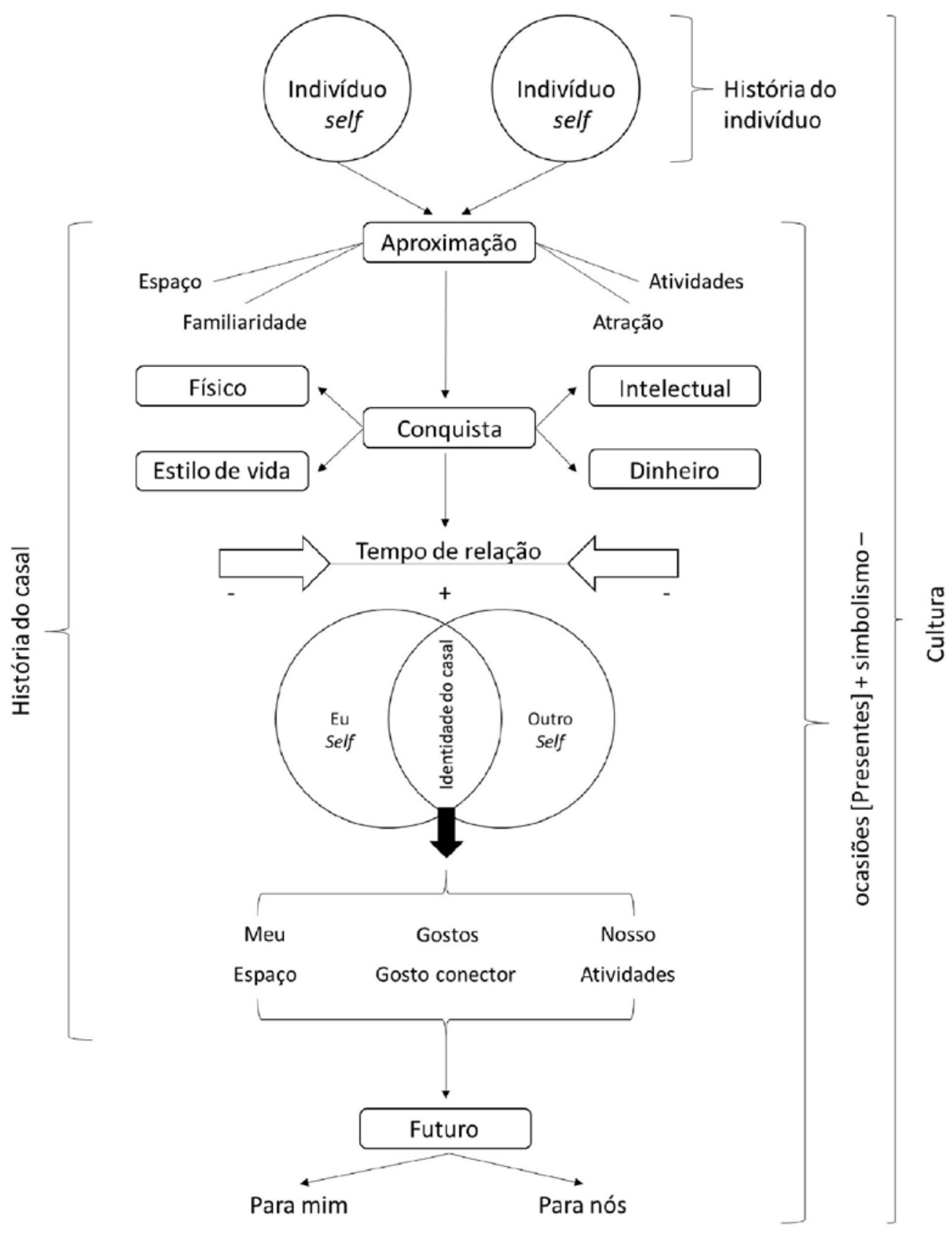

Fonte: Elaborado pelos próprios autores

A primeira parte do esquema teórico diz respeito a constituição dos indivíduos como pessoas que estão inseridas em um ambiente concebido pela cultura e suas significações. Neste momento, cada indivíduo possui a sua história, que é tudo aquilo que foi vivido antes de se constituir o par, isto inclui relacionamentos anteriores, vivências familiares, trajetória profissional, etc. O que este indivíduo traz consigo de outros relacionamentos e vivências interfere diretamente na formação de novos relacionamentos. Este passado se conecta à maneira pela qual experimentam os relacionamentos atuais, demonstrando aí alguma influência do processo de socialização proposto por John (1999) e Ekström (2015). Segundo os autores, a socialização ocorre durante toda a vida de uma pessoa e pode ser dividida em duas, a socialização primária, que é aquela que é vivenciada na infância, cuja função é preparar o indivíduo para a vida em sociedade, e a socialização secundária, que é aquela que ocorre no seio das vivências de um adulto em diferentes contextos, especialmente o trabalho. 
Os entrevistados frequentemente relatavam experiências de consumo que ocorreram na infância ou adolescência sem que fossem solicitados a fazê-lo. A experiência de consumo na infância ou adolescência chega a ser apontada como influenciadora do comportamento de consumo atual, em consonância com o pensamento de Ward (1974) e John (1999). Alguns entrevistadosrelataram hobbies do passado que os acompanham até o presente. Estes hobbies normalmente foram construídos na infância e adolescência e apareceram conectados ao senso de identidade. Para que façam parte do senso de identidade, os bens precisam adquirir um significado que vai além de sua função utilitária. Para Douglas e Isherwood (2004), os bens excedem seu valor comercial, de status e utilitário por meio de seus significados, operando na esfera material e cognitiva.

O meu hobby preferido sempre foi música e desde jovem eu comprava muito $C D$. Eu tenho aqui um monte de $C D$, um quarto, coleção mesmo de CD, DVD dos artistas que eu gosto. Cara, eu gastei mais dinheiro foi com CD, eu acho (E12).

Nas relações amorosas, o padrão de vida experimentado por ambos se funde e isso pode provocar algum nível de estranhamento ou prazer de experimentar o que o outro traz para dentro da relação. A fusão dos padrões de vida ou identidades em direção a uma percepção de mundo que faça sentido aos dois pode ser compreendida pelo senso de self-estendido de Belk (1988), um conceito importante para esta pesquisa que é desenvolvido mais adiante.

Bom, o meu primeiro namorado era um homem mais velho... ele era meio equilibrado... E ele que me ensinou muito isso também, eu acho. Verdade, eu acho que ele que me ensinou a ter pé no chão, a economizar... $E$ isso me marcou bastante assim. Eu admiro pessoas assim (E1).

Porque... Nossa, eu conheci tanta coisa ultimamente, que eu nem sabia que ... tinha, sabe? Bistrô... E ele gosta muito de vinho, entende de vinho... Eu acho isso bacana, está na moda, né, essa coisa de vinho. Eu não entendo muito. Aprecio, bebo, tudo, mas não entendo (E1).

Na segunda parte do esquema, os dados mostraram que a aproximação do casal pode ser facilitada pelo grau de intimidade que foi estabelecida com o parceiroou pelo fato de frequentarem espaços comerciais que reflitam parte da identidade construída por ambos. Sentir-se confortável em determinado local é parte importante de uma aproximação afetiva, ou seja, o senso de pertencimento ao contexto provoca o conforto necessário para que ambos possam se concentrar na conversa e se conectarem.

Se você gosta muito de balada, por que não? Você pode encontrar alguém legal numa balada. Se você gosta muito de programas culturais, se você é uma pessoa culta, gostaria de um namorado culto, frequente ambientes cultos. É muito... A probabilidade de você encontrar uma pessoa parecida com você, com as mesmas afinidades, é muito maior. Assim, eu sempre pensei nisso (E11).

É justamente nestes locais que o conhecimento sobre o outro se aprofunda. Neste momento, as atividades ou gostos que cada um possui são relevados gradualmente. Faz parte da aproximação conhecer um pouco mais da singularidade do outro. Gostos musicais, gastronômicos, de vestuário, hobbies, etc. costumam ser os primeiros e mais facilmente observados, normalmente, temas de muitas conversas introdutórias. Assim, o consumo possui força de expressão que permite reconhecer o outro e já neste momento apresenta sua força como tal. O próprio local escolhido por um tende a refletir parte desses gostos ao mesmo tempo em que envia alguma mensagem parao outro. Dessa forma, as menores atitudes são observadas com atenção, é por meio delas que se mede a afinidade para decidir acerca da possibilidade de se continuar ou não com a aproximação. "Aí a gente começou a conversar, eu vi que era uma pessoa inteligente, que tinha tudo a ver comigo e tal" (E6).

A atração física é outro ponto importante em uma aproximação. Parece haver algum tipo de métrica pessoal para cada pessoa, que determina se alguém é habilitado para ser seu par se estiver dentro de uma faixa de atração física específica e muito particular. Ainda que o padrão de beleza ditado pelos meios de comunicação esteja em aderência a uma certa unanimidade quanto a classificação do belo, existe também 
aquilo que se pode chamar de padrão de beleza singular, que parece conviver em harmonia com o padrão de beleza difundido com mais força pela mídia. A aproximação ocorre se a atração está presente.

Ah, eu costumo falar que o belo não me atrai. Eu tenho algumas excentricidades. Dentre elas o belo propriamente dito não me atrai. Eu tenho gostos bem particulares. Uma mulher para me chamar atenção, ela tem que ter alguma coisa que foge do padrão convencional de beleza (E14).

A aproximação é algo que antecede à conquista, terceira parte. Foi percebido que os elementos mais destacados podem ser nomeados como físico, estilo de vida, intelectual e dinheiro. O físico envolve a importância da aparência e a maneira pela qual determinado indivíduo gere a própria aparência, ou seja, são observados os cuidados pessoais e certo tom de estilo físico, como charme, uso da moda, comunicação corporal, tom de voz e olhar.

O estilo de vida determina a compatibilidade plena do casal e pode ofertar valiosas informações acerca da afinidade de ambos. Os conhecimentos, práticas e atividades são conhecidos, mensurados e muitas vezes absorvidos, novamente o consumo aparece em destaque. As entrevistas revelaram que a importância da afinidade é muito alta. Isso quer dizer que a afinidade, na perspectiva dos entrevistados, não envolve apenas aspectos de ordem pragmática e cotidiana, mas atravessa por questões subjetivas, como o intelecto. A maneira que se lida com questões relacionadas ao dinheiro é facilmente percebida pelos indivíduos e é muito importante no processo de conquista. É preciso sentir certa afinidade também neste aspecto. Pessoas descontroladas ou financeiramente desorganizadas representam baixa possibilidade de consolidação de uma relação amorosa.

Foi possível perceber que existem gostos singulares que podem se fundir ou permanecerem singulares, gostos que podem ser criados e algum ou alguns gostos que conectam o casal fortemente, permitindo a manutenção da relação ao delinear o "meu, o nosso e o gosto conector". Os fragmentos a seguir retratam essa questão.

...Eu cresci com essa... né, com vida mais simples. Igual, eu brinco assim, que hoje... Igual, o namorado gosta muito de champanhe, essas coisas. $E$ aí eu não tenho esse paladar assim, porque eu gosto mesmo é da minha cachacinha, cervejinha... Eu sou bem simples quanto a isso. Mas, assim, essa nova vida aí está interessante (E1).

Então, eu não como carne, e ele come, né? Mas não querendo influenciar o gosto dele, ele come muitas coisas sem carne. E gosta. Assim, descobriu que é gostoso também comer sem carne. Então, às vezes ele abre mão da carne, para comer alguma coisa comigo (E11).

Todos esses gostos envolvem os espaços em que são vivenciados e as atividades que os envolvem. Os espaços podem ser privados e públicos, e ainda dentre esses, compartilhados com amigos e/ou desconhecidos ou simplesmente vividos apenas pelo casal. As atividades envolvem os tipos de gostos em si e as experiências que promovem, residindo aí a possibilidade de significação individual ou em casal, formando aí a identidade do indivíduo e a do casal.

Assistir jogo. Dois fanáticos por futebol (E4).

Vinho tinto. Nós dois adoramos (E6).

Nos estudos de consumo, as posses são entendidas como parte da identidade do indivíduo, funcionando como força de sua expressão. Entretanto, é preciso compreender, primeiramente, o sentido de posse. $O$ princípio que permite tal compreensão reside no reconhecimento, consciente ou inconsciente, das posses como parte de nós mesmos. Algo que é chamado de nosso é a soma de nós mesmos (BELK, 1988). As posses vão além da concepção da propriedade de bens materiais de um indivíduo, elas se estendem às pessoas, lugares e posses em grupos, que juntas, formam a metáfora do self-extendido, uma representação identitária que deixa de ser percebida apenas emnível do indivíduo e passa a se estender por elementos que formam o seu universo. 
Sob esta perspectiva, apenas um conjunto completo de itens de consumo será capaz de representar os diversos aspectos de alguém, ainda que incongruentes (BELK, 1988). Belk (1988) usa o termo "self", "senso de si" e "identidade" como sinônimos para a forma como alguém percebe subjetivamente quem ele é. O autor acredita que qualquer elucidação do que está incluso no self pode ser aplicado indistintamente em indivíduos e culturas, já que a constituição do eu é uma avaliação subjetiva que muda entre as pessoas e com o tempo (AHUVIA, 2005).

Esta fusão entre indivíduos e posses, quarta parte do esquema, se confunde com os significados de ser ou ter, que juntos assumem um sentido de identidade. Entretanto, não é possível pensar que estamos a todo tempo nos apropriando de itens que nos representam. Aron et al. (1991) apresentaram um estudo acerca de relacionamentos próximos e a inclusão do outro no self. A pesquisa sugeriu que as representações cognitivas do eu e do outro são muito mais fortes quando ambos estão em estreita ligação, ou seja, a relação amorosa envolve uma fusão, nunca plena, de identidades em que o self se expande para a inclusão do outro.

O senso de identidade é, frequentemente, estruturado por meio de narrativas (FOURNIER, 1998; GIDDENS, 2002) que mesclam atributos e memórias importantes dos indivíduos. Tal linha histórica permite a construção do sentido de identidade por meio do passado, presente e expectativas futuras, locais em que o consumo aparece como escape da identidade. A vantagem em compreender a identidade como um núcleo que pode ser comparado consiste na possibilidade de moldá-la e visualizá-la como algo que continuamente se modifica (AHUVIA, 2005).

Esses programas, digamos, mudaram um pouco do início até hoje. No início era você sair para um barzinho, uma festa de algum amigo em comum, de repente ir a um cinema, alguma coisa assim, almoçar em algum lugar, jantar em algum lugar, basicamente isso. Agora as coisas estão mais, digamos, formais, né? A gente procura sair. Mas hoje, às vezes, é um compromisso social que a gente tem, festas de família, festas de amigos, etc. (E14).

Ao assumirmos que o consumo permeia a identidade, a importância do que foi chamado de "gosto" fica evidente. Foi percebido que, nas relações amorosas, a apresentação de um indivíduo por meio de seus relatos de "gostos" constitui-se como um elemento que oferecerá ao outro as informações necessárias para a construção da percepção de identidade de quem se apresenta. Trata-se de uma via de mão dupla que, no caso das relações amorosas, incidirá na fusão de identidades no momento em que "gostos" parecidos são descobertos ou a construção de novos gostos é realizada a dois. O gosto que se destaca nesta construção, por ser representativamente forte para o casal, foi chamado de gosto conector. Nas entrevistas, os gostos conectores apareceram vinculados a itens de alimentação, bebidas, viagens, cuidados pessoais, espiritualidade, vestuário e consumo de entretenimento, refletindo nos atos de presentear.

$\mathrm{O}$ ato de presentear tem sido descrito em diversos contextos histórico-culturais da humanidade, demonstrando sua vocação enraizada nos costumes de sociedades muito antigas. Por se tratar de um costume universal (MAUSS, 2003; SCHWARTZ, 1967), desperta interesse em pesquisadores de diversos campos, como a sociologia e antropologia (COELHO, 2006; MAUSS, 2003), psicologia (SCHWARTZ, 1967) e o marketing (BELK and COON, 1991; QIAN, RAZZAQUE, KENG, 2007; SHERRY, 1983; WOLFINBARGER, 1990). No Brasil, é possível encontrar estudos sobre o tema em pesquisas como as de Pepeceet al. (2006), Lourenço e Rezende (2012) e IsboliePepece (2015). Nas relações amorosas, a reciprocidade do presentear adquire contornos ainda mais sensíveis, pois contribui para a manutenção da relação. A reciprocidade do ato presentear é associada ao sistema de dádivas de Mauss (2003), no qual o dar, receber e o retribuir conferem seu sustentáculo. O simbolismo e a obrigação se apresentam como duas esferas da motivação do presentear. A obrigação pode ser entendida no âmbito da reciprocidade ou pelos rituais. A reciprocidade se destina a oferecer um retorno do presente anteriormente recebido, não necessariamente vinculados a um contexto. Os rituais correspondem as normas sociais, relações culturalmente constituídas e compartilhadas, normalmente associadas a situações específicas, como os ritos de passagem, muitas vezes delineando até mesmo o tipo e o preço dos presentes (GOODWIN, SMITHandSPIGGLE, 1990; WOLFINBARGER, 1990).

[...] De identificar que está indo tudo bem na relação, né? Isso. Porque, quando a gente; gosta, a gente tenta agradar de tudo quanto é forma. Eu sou assim, se eu gostar. Por 
exemplo, se eu gostar de você, eu tento te agradar em tudo. Eu tento ser perfeita em tudo, entendeu? Nos presentes, sabe? Tudo, tudo. Então, assim, quando a gente gosta, a gente demonstra (E5).

Presentear dispensa energia do indivíduo que inicia sua execução, carregando de elementos peculiares de quem o faz (MAUSS, 2003). Suas múltiplas possibilidades de significação estão estreitamente vinculadas ao grau de intimidade entre quem concede e quem recebe o presente, facilitando a percepção das motivações entre eles (WOLFINBARGER, 1990) e a intensidade das relações entre os envolvidos (SHERRY, 1983). No campo das emoções do amor romântico, presentes e despesas refletem o desejo por fazer o possível para agradar a pessoa amada. A reciprocidade não é um problema, mas a expressão é (BELK and COON, 1991). Aqui, os presentes precisam demonstrar que o destinatário é único e especial, encontrando nos presentes originais a via de sua expressão, tornando-os cada vez mais imbuídos de simbolismo. Mas para isso é preciso altruísmo, sacrifício. O doador está disposto e ansioso para levar sua felicidade ao outro e as emoções dominam tais ofertas. Os presentes perpassam por desejos de vivências futurasque podem ocorrer a nível individual ou da relação, muitas vezes demonstrando o que se espera desse futuro, que pode ser compreendido como uma visualização do estado em que o indivíduo e o casal almejam estar.

Uma viagem. Seria lindo. O melhor presente da minha vida seria esse (E7).

Acho que a minha aliança de noivado, que ele não quer me dar de jeito nenhum (E8).

Nossa casa. [...] Aí seria um presente perfeito, entendeu? Mais que perfeito (E5).

Os planos para o futuro, parte final deste esquema, são carregados de desejos que são trazidos pelo indivíduo para dentro da relação e desejos construídos a dois, ou seja, é percebido que o indivíduo já possui sua própria idealização de futuro para si, entretanto, o relacionamento pode acrescentar ou mudar tais anseios. Assim, os desejos que são levados para uma relação podem ser alterados ou reforçados por influência do outro, o importante aqui é que o outro caiba na esfera de desejos individuais de futuro. Caso isso não ocorra, existe a tendência a ver pouca possibilidade de continuidade na relação. Logo, parece existir uma certa tendência em se separar o que é meu e o não-meu também na esfera do futuro, realçando a concepção de que o self-estendido em casal é sempre parcial e nunca plenamente incorporado.

O meu futuro ele discute muito comigo, ele me apoia demais. Se eu quiser fazer medicina, ele falou que me apoia totalmente, eu largar tudo para poder fazer. E a gente discute muito o futuro. Assim, a gente planeja muita coisa junto. A gente pensa muito o que a gente estará fazendo daqui tantos anos (E8).

Normalmente, os planos de futuro do casal envolvem benefícios para ambas as partes e estão conectados a elementos que demonstrem segurança, manutenção e união na relação. Para tanto, elementos do tempo presente, como os presentes, podem conferir especial demonstração de apoio ao futuro individual e conjunto. Por fim, os objetivos deste trabalho serão revistos nas considerações finais, concluindo o debate que esta discussão almejou apresentar até o momento.

\section{Considerações finais}

Ao chegar às considerações finais, torna-se importante retornar à lacuna teórica que motivou a execução da presente pesquisa e defender a ideia de que o artigo buscou trazer uma contribuição original para os estudos de cultura e consumo. Ou seja, cabe salientar que o artigo tentou, por meio da pesquisa empírica conduzida com indivíduos em início de relacionamento, discutir de que forma o consumo está presente e influencia a vida das pessoas na esfera dos relacionamentos amorosos. Os resultados expostos e discutidos anteriormente acabaram por trazer contribuições para o campo da cultura e consumo que merecem ser destacados aqui.

Em primeiro lugar, foi possível perceber que cada relacionamento permite conferir ao ser algum tipo de experiência única, proporcionando algum grau de aprendizado. A maneira pela qual o indivíduo vivencia tais aprendizados influenciará a maneira pela qual ele irá lidar com os relacionamentos e o consumo. 
Em segundo lugar, os resultados discutidos na seção anterior jogaram luz na noção de que como o consumo está inserido em um contexto cultural que o utiliza como força de expressão de identidade, ele acaba funcionando como elemento que permite reconhecer o outro e avaliar as possibilidades de constituir algum grau de intimidade com este alguém. Assim, o consumo é fundamental e perpassa por diversos aspectos, desde a roupa em que se usa, o conhecimento que se apresenta ter, a experiência de vida que se demonstra, os costumes alimentícios, as viagens que se fez e se costuma fazer, as músicas que se consome, os lugares que se frequenta, os hábitos de compra usuais, tudo pode ser usado como elemento para se entender o outro.

Em terceiro lugar, foi possível perceber que cada um dos membros formadores de um casal possui seu próprio universo de experiências, que neste trabalho foi chamado de self. Esse universo pode ser expandido para acomodar outra pessoa e parte de seu universo, formando a integração parcial de identidades reconhecida aqui como identidade do casal. Ou seja, a identidade do casal é fruto do aprofundamento do conhecimento do outro e da gradual fusão dos estilos de vida. É neste momento que o debate acerca do selfestendido na proposta de Aron et al. (1991) se evidencia. O estreitamento da ligação interpessoal promove uma fusão de identidades em que o self se expande para a inclusão do outro, ainda que sempre haja uma zona que pertença apenas ao indivíduo, novamente, o que é meu e o não-meu ajuda a demarcar esta zona. Quanto aos presentes, algo que emergiu na pesquisa de campo, eles se tornam uma via de expressão de mensagens não verbais desde o momento em que indica algum interesse na aproximação até o momento em que expressa desejos mais sólidos para a construção de momentos futuros entre o casal.

Em suma, a grande contribuição teórica repousa na constatação de que o consumo está tão imbricado na vida da sociedade contemporânea que sua presença e interferência se torna marcante e até mesmo essencial na esfera dos relacionamentos amorosos entre os casais. Complementarmente, o estudo ainda apresenta questões que confirmam a noção de que os significados do consumo para ambos os indivíduos são (re)construídos por meio dos relacionamentos amorosos.

Vale lembrar que o arcabouço teórico oriundo da Consumer CultureTheory foi essencial para que este trabalho pudesse ser realizado no marketing com temáticas já exploradas e incentivadas pela CCT, self, identidade, presentes, socialização e amor encontram abertura e trabalhos realizados no campo da CCT, o que permitiu maior sustentação na escolha de autores e segurança durante o percurso de pesquisa.

Torna-se importante enfatizar que o trabalho também traz contribuições interessantes para o campo uma vez que oferece aos pesquisadores de cultura e consumo um esquema teórico no qual são articulados diversos conceitos caros ao campo tais como identidade, gosto, doação de presentes na perspectiva do consumo enquanto construção social e cultural. Não se pode esquecer, todavia, que a construção desse esquema contou com o apoio de vários elementos metodológicos propostos pela groundedtheory em sua vertente interpretativista defendida por Charmaz (2009). A metodologia mostrou-se adequada e alinhada com a proposta do trabalho e pode servir de inspiração para outros estudos do campo da Consumer CultureTheory.

Além dessas contribuições, o trabalho ainda fez emergir uma série de possibilidades de pesquisas futuras. Seria interessante refletir como o aumento contínuo de comunicação e intimidade do casal se refletem no ato de presentear. A maneira pela qual os presentes se modificam ao longo de muitos anos de relacionamento ofereceria outra boa oportunidade de pesquisa. O estudo com outras formações de relações amorosas também seriam interessantes possibilidades para futuras pesquisas, casais homossexuais, casais formados na terceira idade, divorciados ou mesmo um estudo comparativo entre homens e mulheres de um mesmo casal ou apenas com homens, são alguns desses exemplos. Casais com culturas distintas e que possuem pouco tempo de relação configuram-se como bons candidatos a interessantes projetos de pesquisa. A influência do contexto urbano em que estão inseridos determinados casais seria um relevante tema de estudos. O interesse aqui residiria na percepção de como lojas, restaurantes, shoppings e outras atividades de consumo urbanas influenciam na formação de casais de determinada região. Além disto, pesquisas de cunho quantitativo poderiam ser aplicadas obtendo o esquema teórico criado neste trabalho como base. Este tipo de trabalho conferiria maior peso à contribuição teórica aqui oferecida e poderia enriquecê-la ou melhorá-la. 
Trabalhos relacionados às fases de aproximação, conquista e consolidação poderiam ser realizados separadamente, levando em consideração os tipos de presente, por exemplo, ou/e os aspectos que rodeiam essas fases em diferentes tipos de abordagem de pesquisa, como a quantitativa. Além disto, maneira pela qual os presentes representam o futuro da relação e em estudos mais pontuais, como a dinâmica de consumo se modifica com as alterações de hábitos relacionados às dietas alimentares, cuidados médicos com o corpo, alergias, estudos, mudança de trabalho, adoção de um animal de estimação, planos financeiros de um dos pares em função de um sonho particular, perda de fonte de renda, etc. Enfim, existem muitas possibilidades futuras que poderiam advir dos debates aqui ofertados e que permitiram compreender cada vez como as questões individuais e sociais confluem em um ambiente de mercado.

\section{Referências}

AHUVIA, A. C. Beyond the Extended Self: Loved Objects and Consumers' Identity Narratives. Journal of Consumer Research, v. 32, p. 171-184, 2005.

ARNOULD, E.; THOMPSON, C. J. Consumer Culture Theory (CCT): Twenty Years of Research. Journal of Consumer Research, v. 31, n. 4, p. 868-882, 2005.

ARNOULD, E.; THOMPSON, C. J. Consumer Culture Theory (and we really mean): dilemmas and opportunities posed by an academic branding strategy. In: Belk, R. W., \& Sherry Jr., J. F. Consumer Culture Theory. Oxford: Elsevier, 2007.

ARON, A., ARON, E. N., TUDOR, M.; NELSON, G. Close Relationships as Including Other in the Self. .JournalofPersonalityand Social Psychology, v. 60, n. 2, p. 241-253, 1991.

BARBOSA, L. Sociedade de Consumo (1a ed). Rio de Janeiro: Jorge Zahar Editora, 2004.

BARDIN, L.Análise de conteúdo. Tradução de Luís Antero Reto e Augusto Pinheiro. Lisboa: Edições, 1977.

BAUDRILLARD, J. A Sociedade de Consumo. (70a ed.). Rio de Janeiro: Elfos, 1995.

BAUER, M. W.; GASKELL, G. Pesquisa qualitativa com texto, imagem e som (5a ed.). Petrópolis: Vozes, 2002.

BEALL, A. E.; Sternberg, R. J. The social construction of love. Journal of Social and Personal Relationships, v. 12, n. 3, p. 417-438, 1995.

BELK, R. W.; COON, G. Can't buy me love: dating, money, and gifts. Advances in Consumer Research, v. 18, n. 1, p. 521-527, 1991.

BELK, R. W.; GREGORY S. C. Gift giving as agapic love: an alternative to the exchange paradigm based on dating experiences. Journal of Consumer Research, v. 20, n. 3, p. 393-417, 1993.

BELK, R. W.; WALLENDORF, M. The Sacred Meanings of Money. Journal of Economic Psychology, v. 11, p. $35-67,1990$.

BELK, R. W. Possessions and the extended self. Journal of Consumer Research, v. 15, n. 2, p. 13968, 1988.

BELK, R. W.; FISCHER, E.; KOZINETS, R. V. Qualitative Consumer \& Marketing Research (1a ed.). Los Angeles: Sarge, 2013.

CAMPBELL, C. A Ética Romântica e o Espírito do Consumismo Moderno. (1a ed.). Rio de Janeiro: Rocco, 2001.

CAMPBELL, C. Cultura, consumo e identidade. Eu compro, logo sei que existo: as bases metafísicas do consumo moderno. In: BARBOSA, L. \& C. CAMPBELL, C. (Orgs.). Cultura, consumo e identidade. Rio de Janeiro: FGV, 2006.

CHARMAZ, K. A construção da teoria fundamentada (1a ed.). Porto Alegre: Artmed, 2009. 
CHURCHILL, G. A. Marketing Research Methodological Foundations.(5a ed.). Chicago: Dryden, 1991.

COELHO, M. C. O Valor das Intenções: Dádiva, Emoção e Identidade. Rio de Janeiro: FGV, 2006. COSTA, S. Amores Fáceis: Romantismo e Consumo na Modernidade Tardia. Novos Estudos CEPBRAP, v. 73, p. 111-124, 2005.

CRESWELL, J. W. Investigação Qualitativa \& Projeto de Pesquisa. (3a ed.). Porto Alegre: Penso, 2014.

DENZIN, N. K.; LINCOLN, Y. S. O Planejamento da Pesquisa Qualitativa. (2a ed.). Porto Alegre: Bookman, 2006.

DESJEUX, D. O Consumo: Abordagens em Ciências Sociais. Maceió: Edufal, 2011.

DONOGHUE, S. Projective Techniques in Consumer Research. Journal of Family Ecology and Consumer Sciences, v. 28, p. 57-53, 2000.

DOUGLAS, M.; ISHERWOOD, B. O mundo dos Bens. Rio de Janeiro: UFRJ, 2004.

EKSTRÖM, K. M. Consumer Socialization Revisited. Research in Consumer Behavior, v. 10, p. 71-98, 2015.

FLICK, U. Uma introdução à Pesquisa Qualitativa (2a ed.). Porto Alegre: Bookman, 2004.

FOURNIER, S. Consumers and Their Brands: Developing Branding Theory in Consumer Research. Journalof Consumer Research, v. 24, p. 343-73, 1998.

GAIÃO, B. F. S., SOUZA, I. L.; LEÃO, A. L. S. Consumer CultureTheory (CCT) já é uma Escola de Pensamento em Marketing? Revista de Administração de Empresas, v. 52, n. 3, p. 330-344, 2012.

GER, G.; BELK, R. W. Accounting For Materialism In Four Cultures. Journalof Material Culture, v. 4, n. 2, p. 183-204, 1999.

GIDDENS, A. Modernidade e Identidade. Rio de Janeiro: Zahar, 2002.

GOODWIN, C., SMITH, K. L.;Spiggle, S. Gift-Giving: Consumer Motivation and the Gift Purchase Process. In: Advances in Consumer Research, Association for Consumer Research, v. 17, p. 690-698, 1990.

GREEN, J. Approaching the Core of Consumer Behaviour. Marketing Research,v. 19, n. 20, p. 649-656, 1984.

GUEDES, D.; Assunção, L. Relações amorosas na contemporaneidade e indícios do colapso do amor romântico (solidão cibernética?). Revista Mal-EstareSubjetividade, v. 6, n. 2, p. 396-425, 2006.

HAIRE, M. Projective Techniques in Marketing Research. Journal of Marketing, v. 14, p. 649-56, 1950.

HARRIS, M. The Rise of Anthropological Theories. Londres: Routledge\&Kegan Paul, 1969.

ILLOUZ, E. O amor nos tempos do capitalismo (1a ed.). Rio de Janeiro: Zahar, 2011.

ISBOLI, G. H. P.; PÉPECE, O. M. C. Presentes que o Público Jovem Masculino não Gosta de Ganhar. RAIMED - Revista de Administração IMED, v. 4, n. 2, p. 206-219, 2015.

JOHN, D. R. Consumer Socialization of Children: A Retrospective Look at Twenty-Five Years of Research. Journal of Consumer Research, v. 26, p. 183-213, 1999.

KOZINETS, R. V. Utopian Enterprise: Articulating the meaning of Star Trek's culture of consumption. Journalof Consumer Research, v. 28, n. 1, p. 67-89, 2001.

LARAIA, R. B. Cultura, um conceito antropológico (1a ed.). Rio de Janeiro: Zahar, 2002.

LIPOVETSKY, G. A Felicidade Paradoxal: ensaios sobre a sociedade de hiperconsumo (1 ${ }^{\mathrm{a}}$ ed.). São Paulo: Companhia das Letras, 2007. 
LOURENÇO, C. D. S.; REZENDE, D. C. Vale-Presente: Como Fica a Dimensão simbólica do Ato de Presentear? Contextus - Revista Contemporânea de Economia e Gestão, v. 10, n. 1, p. 99-115, 2012.

MAUSS, M. Ensaio Sobre a Dádiva, Forma e Razão da Troca nas Sociedades Arcaicas. MAUSS, M. Sociologia e Antropologia. São Paulo: Cosac Naify, 2003.

McCRACKEN, G. Cultura e Consumo. Rio de Janeiro: Mauad, 2003.

McCRACKEN, G. Cultura e Consumo: Uma explicação teórica da estrutura e do movimento do significado cultural dos bens de consumo. Revista de Administração de Empresas, v. 47, n. 1, p. 99115, 2007.

MILLER, D. Consumo como Cultura Material. Horizontes Antropológicos, v. 13, n. 28, p. 33-63, 2007. PÉPECE O. M. C. et al. Comportamento do Consumidor: Ato De Presentear com Jóias na Cidade de Curitiba. Administração de Empresas em Revista, v. 5, p. 31-62, 2006.

PINHEIRO, M. C. T. Publicidade: a procura amorosa do consumo. Comunicação, Mídia e Consumo, v. 3, n. 8, p. 169-187, 2006.

PINTO, M. R.; LARA, J. E. As experiências de consumo na perspectiva da teoria da cultura do consumo: identificando possíveis interlocuções e propondo uma agenda de pesquisa. Cadernos EBAPE.BR, v. 9, n. 1, p. 37-56, 2011.

PINTO, M. R.; SANTOS, L. L. S. A GroundedTheory como Abordagem Metodológica: relatos de uma experiência de campo. Organizações\&Sociedade, v. 19, n. 62, p. 417-436, 2012.

QIAN, W., RAZZAQUE, M. A.; KENG, K. A. Chinese cultural values and gift-giving behavior. Journalof Consumer Marketing, v. 24, n. 4, p. 214-28, 2007.

ROCHA, E. P. Q. Totem e consumo: um estudo antropológico de anúncios publicitários. Rio de Janeiro: Revista ALCEU (PUC-RIO), v. 1, n. 1, p. 18- 37, 2000.

SAUERBRONN, J. F. R.; AYROSA, E. A. T.; BARROS, D. F. Bases sociais das emoções do consumidor: uma abordagem complementar sobre emoções e consumo. Cadernos EBAPE.BR, v. 7, n. 1, p. 169-82, 2009.

SCHWARTZ, B. The Social Psychology of the Gift. American Journal of Sociology, v. 73, p. 1-11, 1967.

SHERRY, J. F. Gift Giving in Anthropological Perspective. Journal of Consumer Research, v. 10, p. 157-168, 1983.

STRAUSS, A.; CORBIN, J. Pesquisa qualitativa: técnicas e procedimentos para o desenvolvimento de teoria fundamentada (2a ed.). Porto Alegre: Artmed, 2008.

VERGARA, S.; CALDAS, M. Paradigma Interpretativista: a busca da superação do objetivismo funcionalista nos anos 1980 e 1990. Revista de Administração de Empresas, v. 45, n. 4, p. 66-72, 2005.

WARD, S. Consumer Socialization. Journal of Consumer Research, v. 1, p. 1-14, 1974.

WARDE, A. Consumption: a sociological analysis. London: Palgrave Macmillan, 2017.

WOLFINBARGER, M. F.; GILLY, M. C. An Experimental Investigation of Selfsymbolism in Gifts. Advances in Consumer Research, v. 23, p. 458-462, 1996.

WOLFINBARGER, M. F. Motivations and Symbolism in Gift-Giving Behavior. Advances in Consumer Research, v. 17, n. 1, p. 699-706, 1990.

Submetido em: 04/03/2018

Aceito em: 02/09/2019 